\title{
Client Satisfaction with Quality of Prevention of Mother-To-Child Transmission (PMTCT) of HIV Services in The Oti Region Of Ghana: A Facility-Based Cross- Sectional Study
}

Michael Sam

School of Public Health, University of Health and Allied Sciences, Hohoe

Emmanuel Manu ( $\nabla$ emanu@uhas.edu.gh )

University of Health and Allied Sciences https://orcid.org/0000-0002-2724-3649

Judith Anaman-Torgbor

School of Nursing and Midwifery, University of Health and Allied Sciences, Ho

\section{Elvis Enowbeyang Tarkang}

Department of Population and Behavioural Sciences, School of Public Health, University of Health and Allied Sciences, Ho

\section{Research}

Keywords: Satisfaction, PMTCT, HIV/AIDS, Pregnant and Postnatal women, Oti region, Ghana

Posted Date: July 9th, 2021

DOI: https://doi.org/10.21203/rs.3.rs-675008/v1

License: (c) (1) This work is licensed under a Creative Commons Attribution 4.0 International License. Read Full License 


\section{Abstract}

Background: Client satisfaction with the quality of prevention of mother-to-child transmission (PMTCT) of the Human Immunodeficiency Virus (HIV) services is essential if continual utilisation of the services, leading to reduction in MTCT is to be achieved, especially in rural settings of Africa, including Ghana.

Methods. A facility-based descriptive cross-sectional design was adopted, using a pretested semi-structured questionnaire to collect data from a systematic random sample of 567 pregnant women and postnatal mothers receiving PMTCT services from 44 health facilities. Data were analysed using STATA version 14.0 software. Simple frequency and percentages were used to present data on categorical variables. Chi- square was used to determine association between categorical and outcome variables and multivariable logistic regression analyses were conducted to determine the strength of the associations between categorical and outcome variables at a p-value $<0.05$ and a $95 \%$ confidence interval.

Results: The overall satisfaction with PMTCT services among respondents was low (42.7\%). After adjusting the multivariable logistic regression model for confounders, respondents who resided in urban areas [AOR=2.21(95\% Cl: 1.37-3.55); $\mathrm{p}<0.001$ ] and those who experienced no language barrier [AOR=2.86(95\% Cl: 1.88-4.36); $p<0.001]$ were more likely to be satisfied with PMTCT services respectively. Respondents who received services at health centers [AOR=0.33(95\% Cl: 0.18-0.60); $p<0.001]$ and hospitals [AOR=0.41(95\% Cl: 0.23-0.72); $\mathrm{p}=0.002$ ] and women who spend more than an hour in receiving PMTCT [AOR=0.41(95\% Cl: 0.21-0.75); $p=0.004]$ and those who said they would not recommend the PMTCT services to others [AOR=0.25(95\% Cl: 0.22-0.90); $p=0.019]$ were respectively less likely to be satisfied with PMTCT services.

Conclusion: Improvement of PMTCT services in the Oti region should take into consideration the quality of services rendered in hospitals and health centres while striving to reduce the waiting time across all facilities to make clients recommend PMTCT services to others.

\section{Introduction}

The transmission of the Human Immunodeficiency Virus (HIV) from an infected mother to her child during pregnancy, labour, delivery, or breastfeeding is known as mother-to-child transmission (MTCT) [1]. Mother-to-child transmission has created enormous social and economic burden on individuals, families and states, especially in developing countries as it continues to be a major source of HIV infection among children under the age of fifteen years [2]. About $90 \%$ of the estimated 110,000 children newly infected with HIV worldwide occurs in Africa [3]. In Ghana, the National HIV/AIDS Control Programme (NACP) report in 2014 estimated HIV prevalence among pregnant women attending antenatal clinics (ANC) to be $1.6 \%$ whilst many ANC clients remained untested for HIV [4].

To address the problem of MTCT, the prevention of mother-to-child-transmission (PMTCT) of HIV strategy was initiated and has been at the forefront of global public health activities aimed at improving both child and maternal health in relation to HIV/AIDS outcomes [2]. As a result, pregnant women and postnatal mothers attending ANC and post-natal care (PNC) clinics are tested for HIV and provided with the appropriate services against HIV infection of new born babies [2].

The prevention of mother-to-child transmission of HIV is a comprehensive management approach aimed at improving the wellbeing of all women of reproductive age through the provision of HIV screening for all women, prevention of new infection among infants born to HIV-positive mothers and the provision of management for HIV-positive women [5]. The quality of PMTCT services is defined by existence of clear guidance on infant nutrition and the use of anti-retroviral therapy (ART) during pregnancy and lactation, access to the most efficacious regimen by pregnant women, extent of use of regimen, systems in place to monitor programme delivery and patient outcomes [6].

The prevention of mother-to-child transmission has been recognized as vital to saving the lives of young children and reducing infant and child mortality associated with HIV infection [7]. However, the quality of PMTCT services has been found to influence client's utilization and satisfaction towards such services. Clients who are not satisfied with PMTCT services are less likely to utilize such services $[2,9,10]$. As such, client satisfaction with PMTCT services is important in achieving a total elimination of the acquired immune deficiency syndrome (AIDS) by 2030, as set by the world health organization (WHO) and the United Nations [11, 12].

Although several studies have been conducted on client satisfaction regarding PMTCT services on the African continent, most of them focused only on pregnant women attending ANC clinics [8, 13-15]. In Ghana, there is literature paucity on satisfaction with the quality of PMTCT services leaving a knowledge gap on the subject. Some studies conducted in the country either qualitatively explored challenges associated with PMTCT service provision and reasons why clients stay on the PMTCT programmes $[16,17]$ or quantitatively explored the utilization and implementation challenges associated with PMTCT $[7,18]$. Moreover, the Oti region being a novel region, empirical studies on HIV in general and on PMTCT in particular, are yet to be conducted in the region. The current study therefore sought to fill this knowledge gap by assessing client satisfaction with the quality of PMTCT services in the region to better inform policy on the quality of PMTCT services. The study was conceived on the assumption that the quality of both tangible and intangible PMTCT services received by clients could influence their satisfaction with such services, as depicted in Fig. 1.

\section{Methods}

\section{Study Setting}

The study was conducted in the Oti Region of Ghana, in May, 2019. The region covers an area of $11,066 \mathrm{~km}^{2}$, bounded on the North by the Northern Region, South by the Volta Region, East by the Republic of Togo and West by the Volta Lake. The region has a total population of 742,664 with a growth rate of $2.5 \%$ according to the 2019 Ghana statistical report [20]. There are designated facilities for PMTCT services in all the eight districts in the region. PMTCT Loading [MathJax]/jax/output/CommonHTML/fonts/TeX/fontdata.js 
interventions such as HIV testing and counseling, provision of ART, and continuum of care during antenatal, labour and delivery, as well as postpartum services are supposed to be rendered in the region [21]. The Oti region was selected for the study due to the fact that it is a newly created region and adequate number of studies have not been conducted on HIV/AIDS, specifically PMTCT in the region. Hence, quality of PMTCT services rendered in the region needed to be ascertained.

Study Design

This study was a facility-based descriptive cross-sectional study, using a pre-tested paper-based semi-structured interviewer-administered questionnaire, to obtain data on clients' satisfaction with PMTCT of HIV services rendered in the Oti region of Ghana. The questionnaire consisted of three sections; section "A" was on respondent's socio-demographic characteristics, section "B" assessed PMTCT services received by clients and section "C" assessed satisfaction with the quality of PMTCT services received. The questionnaire was pretested on twenty clients from three facilities in the Volta region to assess its appropriateness for the study and also subjected to a Cronbach alpha test. The test resulted in a coefficient of 0.89 for questions on satisfaction on PMTCT services, which indicated the appropriateness of the instrument in measuring the expected outcome, per Taber's interpretation [22]. Respondents' level of satisfaction with PMTCT services was assessed on a 4-point Likert scale; thus, very satisfied (coded 4), satisfied (coded 3), dissatisfied (coded 2) and very dissatisfied (coded 1). An overall satisfaction score was generated using a more composite score of the various variables. Dichotomous variable: satisfied and dissatisfied, was generated from the four degrees of satisfaction and used to run logistic regression analysis. The highest score for the satisfaction variable was 52 and the lowest was 31. A mean of 42.2 was obtained for the satisfaction score. Respondents who had less than the mean score were classified as being dissatisfied with PMTCT services, and those with the mean score and above were classified as being satisfied with PMTCT services [23].

\section{Population and Sampling}

The source population for this study was pregnant women and postnatal mothers who were 18 years or older receiving PMTCT services in forty-four (44) health facilities in the Oti Region of Ghana. Pregnant women and postnatal mothers receiving PMTCT services for up to 6 months and consented to participate were included in the study. However, pregnant women and postnatal mothers who met the inclusion criteria but were seriously ill and required medical attention were excluded from the study. A total of 567 respondents, comprising 424 ANC and 143 PNC attendees were sampled for the study, using the formula; $\mathrm{N}=\frac{\mathrm{Z1}-\alpha / 2^{2} \mathrm{P}(1-\mathrm{P})}{\mathrm{d} 2}$ [24], where $\mathrm{Z1}-\alpha / 2$ is standard normal variate of 1.96 at $95 \%$ confidence interval and a $5 \%$ margin of error; the proportion of clients satisfied with PMTCT services $(P)$, assumed to be $50 \%$ and $d=0.05$, considering an attrition rate of $5 \%$.

All the health facilities comprising public and private hospitals, health centers and CHPS compounds providing PMTCT services in the Oti region were included in the study. The list of all ANC and PNC clients receiving PMTCT services for each facility was obtained and used as the sampling frame. The sample was then proportionately allocated to the selected health facilities based on their registered number of ANC and PNC clients receiving PMTCT services.

Proportional sample was then allocated to each facility per the required sample size. A sampling interval, $k$, was calculate for each facility by dividing the total sample size by the number of registered PMTCT clients per facility. The first participant to be interviewed was selected randomly from table of random numbers and thereafter, every eligible kth person that reported for PMTCT services at the ANC or PNC clinic was selected until the clinics closed for the day. The process was repeated on every data-collection day until the required sample size for each facility was obtained.

\section{Data Collection Procedure}

Data was collected using a pre-tested semi-structured questionnaire after obtaining ethical clearance from the University of Health and Allied Sciences' Research Ethics Committee. We trained three undergraduate students from the School of Public Health, University of Health and Allied Sciences for two days as field assistants on the data collection tool and data collection procedures. They were informed on the purpose of the study and on ethical procedures to be followed. Data was collected on the socio-demographic characteristics of caregivers, PMTCT services received and clients' satisfaction with those services. Data were collected at the selected centres on daily basis until the required sample size was obtained. The data collectors were supervised on the field by the principal investigator. All interviews were conducted face-to-face.

\section{Study Variables}

The categorical variables of the study were; age, sex, religious affiliation, occupation, highest level of education, marital status, place of residence of respondents as well as type of health facility, gravidity and parity. The outcome variable was satisfaction with PMTCT services.

\section{Data Management and Analysis}

Data were entered into EpiData 3.1 software for cleaning and validation to ensure quality before analysis began. The cleaned data were then exported to Stata version 14.0 for analysis. Simple frequencies and percentages were used for categorical variables. Chi-square was used to determine the association between client's satisfaction (outcome variable) with PMTCT services and the categorical variables (demographic characteristics, structures and processes).

Multivariate logistic regression analysis (C.I of $95 \%$ and p-value) was used to determine the strength of the association between the outcome and categorical variables. Statistical significance was considered based on the $\mathrm{p}$-value $<0.05$ at a confidence interval of $95 \%$. The results were presented in tables and graphs.

\section{Results}

\section{Socio-Demographic Characteristics of Respondents}

Table 1 shows the socio-demographic characteristics of respondents involved in the study. Out of a total of 567 participants, 424 (74.8\%) were pregnant women and $143(25.2 \%)$ were postnatal mothers. The mean ages for the pregnant women and postnatal mothers were $26.8 \pm 6.4$ years and $26.9 \pm 7.6$ years 
had attained Junior High School (JHS) level of education, 428 (75.5\%) were Christians and 193 (34.0\%) were traders. Women residing in semi-urban areas accounted for 225 (39.7\%) and the Ewe tribe accounted for 218 (38.5\%). A slight majority 298 (52.5\%) of the women were multiparous, 284 (50.1\%) were multigravida and 296(52.2\%) received PMTCT services from hospitals. 
Table 1

Socio-Demographic Characteristics of Respondents

\begin{tabular}{|c|c|c|}
\hline Characteristics & Frequency $(n=567)$ & Percentage (\%) \\
\hline \multicolumn{3}{|l|}{ Age group (in years) } \\
\hline $15-24$ & 230 & 40.6 \\
\hline $25-34$ & 260 & 45.9 \\
\hline $35+$ & 77 & 13.6 \\
\hline \multicolumn{3}{|l|}{ Marital status } \\
\hline Married & 452 & 79.7 \\
\hline Divorced & 10 & 1.8 \\
\hline Widowed & 4 & 0.7 \\
\hline Never Married & 101 & 17.8 \\
\hline \multicolumn{3}{|l|}{ Educational status } \\
\hline No Formal Education & 113 & 19.9 \\
\hline Primary & 117 & 20.6 \\
\hline JHS & 211 & 37.2 \\
\hline Secondary & 90 & 15.9 \\
\hline Tertiary & 36 & 6.34 \\
\hline \multicolumn{3}{|l|}{ Religious affiliation } \\
\hline Christian & 428 & 75.5 \\
\hline Islam & 132 & 23.3 \\
\hline Traditional & 7 & 1.2 \\
\hline \multicolumn{3}{|l|}{ Occupation } \\
\hline Housewife & 55 & 9.7 \\
\hline Trading & 193 & 34.0 \\
\hline Farming & 150 & 26.5 \\
\hline Artisan & 118 & 20.8 \\
\hline Civil Servant & 51 & 9.0 \\
\hline
\end{tabular}

Place of residence

\begin{tabular}{|lcc|}
\hline Rural & 167 & 29.4 \\
\hline Semi-Urban & 225 & 39.7 \\
\hline Urban & 175 & 30.9 \\
\hline Tribe & & \\
\hline Ewe & 218 & 38.5 \\
\hline Akan & 155 & 27.3 \\
\hline Guan & 126 & 22.2 \\
\hline Konkomba & 68 & 12.0 \\
\hline Number of children & & \\
\hline Nulliparous & 120 & 21.2 \\
\hline Primiparous & 149 & 26.3 \\
\hline Multiparous & 298 & 52.5 \\
\hline Number of pregnancies & & \\
\hline Primigravida & 164 & 28.9 \\
\hline Secundigravida & 119 & 21.0 \\
\hline
\end{tabular}




\begin{tabular}{|lll|}
\hline Characteristics & Frequency $(\mathbf{n = 5 6 7 )}$ & Percentage $(\%)$ \\
\hline Multigravida & 284 & 50.1 \\
\hline Facility type & \\
\hline Health Center & 194 & 34.2 \\
\hline Hospital & 296 & 52.2 \\
\hline CHPS compound & 77 & 13.6 \\
\hline
\end{tabular}

\section{Prevention of Mother-to-Child Transmission Services Received by Respondents}

Table 2 presents the PMTCT services received by respondents. The most common PMTCT services utilized were; HIV testing 535 ( $94.4 \%$ ), pre-test counselling $500(88.2 \%)$ and post-test counselling 408 (72.0\%).

Table 2

Prevention of Mother-to-Child-Transmission Services Received by Respondents

\begin{tabular}{|lll|}
\hline Variable & $\begin{array}{l}\text { Frequency } \\
\text { ( } \mathbf{n = 5 6 7 )}\end{array}$ & Percentage (\%) \\
\hline Testing for HIV & & \\
\hline Received & 535 & 94.4 \\
\hline Not Received & 32 & 5.6 \\
\hline ART medication & & \\
\hline Received & 22 & 3.9 \\
\hline Not Received & 545 & 96.1 \\
\hline Infant feeding and counselling & \\
\hline Received & 76 & 13.4 \\
\hline Not Received & 491 & 86.6 \\
\hline Pre-test counselling & & \\
\hline Received & 500 & 88.2 \\
\hline Not Received & 67 & 11.8 \\
\hline Post-test counselling & & \\
\hline Received & 408 & 72.0 \\
\hline Not Received & 159 & 28.0 \\
\hline
\end{tabular}

\section{Client Satisfaction with Quality of Prevention of Mother-to-Child Transmission Services Received}

Table 3 presents clients' satisfaction with the quality of PMTCT services received at the health facilities. With respect to the tangible services received, most of the clients were satisfied with the comfortability at the waiting $503(88.7 \%)$ and counselling rooms $538(94.9 \%)$ respectively. Nine out of every ten women 544 (95.9\%) were satisfied with the privacy they received during counselling. The majority $560(98.8 \%)$ of the clients were satisfied with the working environment at the facilities and almost every woman $556(98.1 \%)$ was satisfied with the quality of interaction they had with the service providers. With reference to the intangible services, the majority 501 (88.4\%) and 535 (94.4\%) were satisfied with the waiting time and the duration of counselling session respectively. Seven out of ten women 405 (71.4) had no challenge with the language of communication and were thus satisfied and the majority of pregnant and postnatal women, 511 (90.1\%) and 545 (96.1\%), said the counselling session was beneficial and they would recommend PMTCT services to others respectively. The overall satisfaction with PMTCT services among respondents was $242(42.7 \%)$. 
Client Satisfaction with Quality of Prevention of Mother-to-Child Transmission Services

\begin{tabular}{|c|c|c|}
\hline Variable & Frequency $(n=567)$ & Percentage \\
\hline \multicolumn{3}{|c|}{ Tangible services } \\
\hline \multicolumn{3}{|c|}{ Comfortability of waiting room } \\
\hline Satisfied & 503 & 88.7 \\
\hline Dissatisfied & 64 & 11.3 \\
\hline \multicolumn{3}{|c|}{ Comfortability of counselling room } \\
\hline Satisfied & 538 & 94.9 \\
\hline Dissatisfied & 29 & 5.1 \\
\hline \multicolumn{3}{|c|}{ Privacy in counselling room } \\
\hline Satisfied & 544 & 95.9 \\
\hline Dissatisfied & 23 & 4.1 \\
\hline \multicolumn{3}{|c|}{ Sanitation and hygiene } \\
\hline Satisfied & 560 & 98.8 \\
\hline Dissatisfied & 7 & 1.2 \\
\hline \multicolumn{3}{|c|}{ Interaction with service providers } \\
\hline Satisfied & 556 & 98.1 \\
\hline Dissatisfied & 11 & 1.9 \\
\hline \multicolumn{3}{|c|}{ Intangible services } \\
\hline \multicolumn{3}{|c|}{ Average waiting time } \\
\hline Satisfied & 501 & 88.4 \\
\hline Dissatisfied & 66 & 11.6 \\
\hline \multicolumn{3}{|c|}{ Adequacy of counselling time } \\
\hline Satisfied & 535 & 94.4 \\
\hline Dissatisfied & 32 & 5.6 \\
\hline \multicolumn{3}{|c|}{ Language of communication } \\
\hline Had challenges & 162 & 28.6 \\
\hline No challenges & 405 & 71.4 \\
\hline \multicolumn{3}{|c|}{ Benefit of counselling session } \\
\hline Beneficial & 511 & 90.1 \\
\hline Not Beneficial & 56 & 9.9 \\
\hline \multicolumn{3}{|c|}{ Recommendation of PMTCT services } \\
\hline Yes & 545 & 96.1 \\
\hline No & 22 & 3.9 \\
\hline \multicolumn{3}{|c|}{ Overall satisfaction with quality of РMCTC services } \\
\hline Satisfied & 242 & 42.7 \\
\hline Not satisfied & 325 & 57.3 \\
\hline
\end{tabular}

Predictors Client Satisfaction with Prevention of Mother-to-Child Transmission Services After adjusting the multivariable logistic regression model for confounders in Table 4, respondents who resided in urban areas were 2 times more likely to be satisfied with PMTCT services as compared to those resided in rural areas [AOR $=2.21$ (95\% Cl: 1.373.55): $\mathrm{D}<0.0011$. Respondents who experienced no language barriers when receiving 
PMTCT services were over 2 times more likely to be satisfied with PMTCT services as compared to those who experienced language barriers [AOR = 2.86(95\% Cl: 1.88-4.36); p $<0.001]$. Respondents who received services at health centers and hospitals were $67 \%$ and $59 \%$ less likely to be satisfied with PMTCT services as compared to those who received services at the CHPS compounds [AOR $=0.33(95 \% \mathrm{Cl}: 0.18-0.60)$; $p<0.001]$ and $[A O R=0.41(95 \% \mathrm{Cl}: 0.23-0.72) ; p=0.002]$ respectively. Women who said they spend more than an hour in receiving PMTCT services were $59 \%$ less likely to be satisfied with PMTCT services as compared to those who said they spend less than 30 minutes [AOR = $0.41(95 \% \mathrm{Cl}: 0.21-0.75) ; \mathrm{p}=0.004]$. Respondents who said they would not recommend the PMTCT services to others were $75 \%$ less likely to be satisfied with PMTCT services as compared to those who said they would recommend the services to others [AOR = $0.25(95 \% \mathrm{Cl}: 0.22-0.90) ; p=0.019]$. 


\section{Table 4}

Predictors of Overall Satisfaction with Quality of PMTCT Services

$\begin{array}{llll}\text { Variable Satisfied Dissatisfied } & \begin{array}{l}\text { Chi-Square } \\ \text { value }\end{array} & \begin{array}{l}\operatorname{COR}(95 \% \mathrm{Cl}) \mathrm{p} \text { - } \\ \text { value }\end{array}\end{array}$

Place of

residence

Rural

Semi-Urban

Urban
91(52.0) 84(48)

56(33.5) 111(66.5)

95(42.2) 130(57.8)
$11.94(0.003) * \quad 1$

$1.45(0.95,2.20) 0.081$

$2.15(1.39,3.32) p \leq$ $0.001 *$

Gravidity

Primigravida

59(36.0) 105(64.0)

$5.44(0.066)$

Secundigravida $59(49.6) \quad 60(50.4)$

$\begin{array}{lll}\text { Multigravida } & 124(43 . & 160(56.3)\end{array}$

Language

barrier

Had

Challenges

\begin{tabular}{ll}
\hline $42(25.9)$ & $120(74.1)$ \\
\hline $200(49.4)$ & $205(50.6)$
\end{tabular}

$26.02(P \leq$

1

No Challenges $200(49.4) \quad 205(50.6)$

$2.79(1.86,4.16) p \leq$ $0.000^{*}$

Facility type

CHPS

47(61.0) $\quad 30(39.0)$

12.32

$(0.002)^{*}$

Health centre $\quad 76(39.2) \quad 118(60.8)$

$0.41(0.24,0,71) p \leq$ $0.001 *$

1 


\begin{tabular}{|c|c|c|c|c|}
\hline Variable & Satisfied & Dissatisfied & $\begin{array}{l}\text { Chi-Square(p- } \\
\text { value) }\end{array}$ & $\begin{array}{l}\text { COR }(95 \% \mathrm{Cl}) \mathrm{p}- \\
\text { value }\end{array}$ \\
\hline$<30$ minutes & $163(43.0)$ & $216(57.0)$ & $9.09(0.011)$ * & 1 \\
\hline $\begin{array}{l}30 \text { minutes to } \\
\text { an hour }\end{array}$ & $61(50.0)$ & $61(50.0)$ & & $\begin{array}{l}1.32(0.88 \\
1.99) 0.177\end{array}$ \\
\hline $\begin{array}{l}\text { More than } 1 \\
\text { hour }\end{array}$ & $18(27.3)$ & 48(72.7) & & $\begin{array}{l}0.50(0.28 \\
0.89) 0.018 *\end{array}$ \\
\hline \multicolumn{5}{|l|}{$\begin{array}{l}\text { Recommend } \\
\text { services to } \\
\text { others }\end{array}$} \\
\hline Recommended & 238(43.7) & $307(56.3)$ & $5.61(0.018) *$ & 1 \\
\hline $\begin{array}{l}\text { Did Not } \\
\text { Recommend }\end{array}$ & $4(18.2)$ & 18(81.8) & & $\begin{array}{l}0.29(0.09 \\
0.86) 0.026 *\end{array}$ \\
\hline
\end{tabular}

\section{Discussion}

In this study, we assessed the satisfaction of pregnant and postnatal women regarding the quality of PMTCT of HIV services they received in the Oti Region of Ghana. Our findings revealed that the most PMTCT services received were HIV testing (94.4\%) and counselling ( $94.0 \%)$. High rates of HIV counselling and testing have been reported in other studies conducted in Ghana over the years [21]. HIV counselling and testing seems to be the most popular PMTCT services offered in most African countries. For instance, studies carried out in Ethiopia [2] and Uganda [25] show that HIV testing is the service most received by pregnant mothers as PMTCT service. In Ghana, the current policy guidelines governing PMTCT require that HIV counseling and testing be integrated into reproductive and child health services. Also, all pregnant women accessing reproductive and child health services need to be counselled and tested for HIV by trained counsellors and nurses [4]. Considering the guidelines, there has been missed opportunities for all pregnant women and postnatal mothers to be counselled and tested in the current study, and thus fall short of expectations. Missed opportunities to counsel and test pregnant women for HIV and also initiate those who are positive on ARTs across the country pose challenges to the quest to eliminate mother-to-child transmission of HIV [21].

Satisfaction with PMTCT services was assessed based on satisfaction with tangible and intangible services received. With regards to satisfaction with tangible PMTCT services, respondents were satisfied with all the variables assessed: thus, comfortability of the waiting and counselling rooms, privacy in the counselling rooms, sanitation and hygiene and the quality of interaction they had with service providers. Clients' satisfaction with intangible PMTCT services such as waiting time, adequacy of counseling time, language barrier and beneficence of counselling were also found to be encouraging. It could therefore, be said that PMTCT services provision in the Oti region is satisfactory as clients were satisfied with both tangible and intangible PMTCT services they received. The finding suggests that there is good ambience in health facilities providing PMTCT services in the Oti region as well as good service delivery. This is welcoming, as the role of the quality of tangible and intangible PMTCT services cannot be underestimated. For instance, Lyatuu at al. [8] found that clients' dissatisfaction with PMTCT services in the Dodoma district of Tanzania, was as a result of the poor quality of the tangible and intangible services such as lack of privacy and long waiting time. Other tangible services such as physical structures and warm reception have also been found to influence clients' satisfaction with health services and utilization [26]. Overall, the satisfaction with PMTCT services was $42.7 \%$ in the present study. Thus, although respondents said they were satisfied with the individual PMTCT services they received, cumulatively, they were not satisfied with such services. The current finding disagrees with those of other studies carried out on the continent that showed a higher level of satisfaction with PMTCT services compared to our study $[13,14,27,28]$. The reason for the differences could however be attributed to differences in health systems settings and support across various African countries. Our findings however, fill a knowledge void by empirically ascertaining the actual level of satisfaction with PMTCT services offered in the Oti region of Ghana. The implication of our finding, compared to literature, is that the quality of PMTCT services offered in the region and in the country by extension, should not be assessed as units but as an aggregate, if a true reflection of clients' satisfaction is to be ascertained. It could also be said that if the low level of satisfaction found in the present study is not improved, client utilization of PMTCT services could be affected [29]. Therefore, healthcare providers and authorities in charge of PMTCT services in the Oti region should strive to improve the quality of both tangible and intangible PMTCT services they offer.

With reference to socio-demographic variables that influenced satisfaction with PMTCT services, we found that pregnant women and postnatal mothers who lived in urban areas were 2 times more likely to be satisfied with PMTCT services than those living in rural areas. This finding is not in line with results of a study conducted by Yaya et al. in Ghana [30] which reported no significant differences in level of satisfaction among respondents in rural and urban areas. Also, on the contrary, Farmer et al. [31] from their study conducted in Scotland, reported that clients in rural areas were better satisfied with service provision than those in urban areas. The hiah likelihood of satisfaction found among urban dwelling respondents in the present study could be as a result of disparity in Loading [MathJax]/jax/output/CommonHTML/fonts/TeX/fontdata.js 
the quality of health facilities found in urban and rural Ghana [32]. Comparatively, hospitals equipped with better resources are found in urban Ghana while poorly-resourced health centres and Community-based Health Planning and Services (CHPS) compounds are found in rural parts of the country [33]. Moreover, health care facilities in urban areas are often manned by competent health workers compared to rural health facilities, and this could influence client satisfaction with the quality of service received in these facilities [34].

Respondents without any language barrier were 2 times more likely to be satisfied with the PMTCT service provision. Though a diverse region with varied languages, language barrier seemed not to be a problem in the delivery of PMTCT services. Language barriers pose challenges in terms of achieving high levels of satisfaction among medical professionals and patients, providing high quality healthcare and maintaining patient safety [35]. Findings from a systematic review revealed that language barriers in healthcare lead to miscommunication between the medical professional and patient, reducing both parties' satisfaction and decreasing the quality of health care delivery and patient safety [35]. Deducing from the findings, policy makers in the region should endeavor to address the minor language barrier issues that exist in PMTCT facilities to holistically improve on the overall satisfaction with PMTCT services.

Moreover, respondents who received services at health centers and hospitals were $67 \%$ and $59 \%$ less likely to be satisfied with PMTCT services compared to those who received services from the CHPS compounds. The CHPS initiative aims to make healthcare services including maternal and child health services easily available to rural communities in Ghana [36]. The CHPS compounds are health posts in rural communities that serve as first level of primary care for rural areas, often manned by a nurse or a midwife or both [37]. Hence, there is a lot of interpersonal interaction between CHPS staff and the community members translating into client satisfaction with PMTCT services compared to hospitals, which serve a large number of people per day from different geographical backgrounds. Meanwhile, the issue of dissatisfaction with health care services across hospitals and health centres in Ghana has been a problem of public health concern for some time [38] and often linked to the attitude of hospital staff towards clients. Interpersonal relationship between hospital staff and clients need to be improved if dissatisfaction with PMTCT services rendered at the hospital level is to be addressed. It has also been suggested that dissatisfaction on quality of care at hospitals could be improved by adequate structures, supplies and logistics as well as good communication skills [39].

Furthermore, the present study found that respondents who waited for up to an hour or more to access PMTCT services were $59 \%$ less likely to be satisfied, as compared to those who waited for less than 30 minutes. Waiting time and dissatisfaction with healthcare provision has been well researched [40-42]. As clients have other pressing matters, such as economic ventures, to attend to, spending more time to receive PMTCT services could easily lead to dissatisfaction, as it may lead to loss of income. In order to shorten waiting time, the clinics may be structured such that clients access PMTCT services strictly by appointment. This may ensure that clients do not do not spend more than thirty minutes at health centres to access PMTCT services.

Lastly, respondents who indicated that they will not recommend PMTCT services to others were 75\% less likely to be satisfied with PMTCT services. Recommendation of a service or product to others signifies trust and confidence in such a service or product. The findings suggest that PMTCT service providers do not have loyal clients as a result of dissatisfaction with the quality of services they render. According to Reibstein et al. [43], when a brand has loyal customers, it gains positive word-of-mouth marketing, which is both free and highly effective. This is not the case in the present study as dissatisfied clients are not willing to offer free word-of-mouth marketing of PMTCT services in the Oti region. Client satisfaction should be prioritised by PMTCT service providers in the Oti region in order to improve the uptake of such services and lead to effective prevention of mother to child transmission of HIV in the region.

Potential limitation of this study is that, although measures were taken to interview clients in privacy, conducting the interviews at the various healthcare settings may have given room for response bias in favour of the service providers due to fear of victimisation.

\section{Conclusions}

The overall satisfaction of PMTCT services was low in this study, with HIV counselling and testing being the major PMTCT services received by clients in the Oti region. Client satisfaction with PMTCT services was influenced by their place of residence of clients, language barrier, type facility where PMTCT services are received, waiting time and decision to recommend PMTCT services to others. Hence, PMTCT service providers in the Oti region should endeavor to improve on service in hospitals and health centres while striving to reduce the waiting time across all facilities to make clients recommend PMTCT services to potential clients through free word-of-mouth recommendation.

\section{Abbreviations}

AIDS: Acquired Immune Deficiency Syndrome; Antenatal Clinics: ANC; AOR: Adjusted Odd Ratios; ART: Antiretroviral Therapy; CHPS: Community-based Health Planning and Services; COR: Crude Odd Ratios; HIV: Human Immunodeficiency Virus; NACP: National HIV/AIDS Control Programme; PMTCT: Prevention of mother-to-child transmission; PNC: Post-Natal Care; WHO: World Health Organisation.

\section{Declarations}

\section{Ethics approval and consent to participate}

Approval to conduct the study was obtained from the University of Health and Allied Sciences Research Ethics Committee (UHAS-REC), with identification number UHAS-REC A.5 [6] 18-19, before the commencement of the study. After ethical clearance was obtained, Administrative approval was sought from the Oti Regional Health Directorate and from the heads of the various health facilities where the study was conducted. Before inclusion in the study, a written informed consent was sought from the respondents, after the objectives and nature of the study had been thoroughly explained to potential participants.

\section{Consent for publication}

Loading [MathJax]/jax/output/CommonHTML/fonts/TeX/fontdata.js 


\section{Availability of data and materials}

The datasets generated and/or analysed during the current study are not publicly available due to ethical reasons but are available from the corresponding author on reasonable request.

\section{Competing interests}

The authors declare that they have no competing interests.

\section{Funding}

Not applicable

\section{Authors' contributions}

MS, EM and EET conceived this study. MS collected the data and performed the analysis. MS, EM and JAT drafted the original manuscript. EET, EM and JAT supervised the study from its conception up to write-up and editing. All authors provided resources, read and approved the final manuscript submitted for publication.

\section{Acknowledgments}

We acknowledge the management of the Oti Regional Health Directorate for allowing us to conduct the study in health facilities under their jurisdiction. Sincere thanks also go to all our participants who enabled us to obtain all necessary information toward the publishing of this study.

\section{References}

1. World Health Organization. PMTCT strategic vision 2010-2015: preventing mother-to-child transmission of HIV to reach the UNGASS and Millennium Development Goals: moving towards the elimination of paediatric HIV, December 2009

2. Merga H, Woldemichael K, Dube L. Utilization of prevention of mother-to-child transmission of HIV services and associated factors among antenatal care attending mothers in Sebeta Town, Central Ethiopia. Advances in Public Health. 2016;2016.

3. World Health Organization. Global Health Observatory data. Geneva Switzerland: World Health Organisation; 2018.

4. National AIDS Control Programme. HIV Sero-Sentinel Survey Report, Ghana, Accra. 2014.

5. United Nations Programme on HIV/AIDS. Global Plan towards the Elimination of New HIV Infections among Children by 2015 and Keeping their Mothers Alive.

6. Fund G. The Global Fund to Fight AIDS, Tuberculosis, Malaria. Scaling up prevention of mother-to-child transmission of HIV (PMTCT): Information note.

7. Osei E, Fosu WA, Der J. Assessing the Utilization and Implementation Challenges of Prevention of Mother-to-Child-Transmission of HIV Programme in a Secondary Care Hospital, Ghana.

8. Lyatuu MB, Msamanga GI, Kalinga AK. Clients' satisfaction with services for prevention of mother-to-child transmission of HIV in Dodoma Rural district. East Afr J Public Health. 2008 Dec;5(3):174-9.

9. Sprague C, Chersich MF, Black V. Health system weaknesses constrain access to PMTCT and maternal HIV services in South Africa: a qualitative enquiry. AIDS research therapy. 2011 Dec;8(1):10.

10. Ashipa TO, Ighedosa SU. Assessment of clients' satisfaction with the PMTCT counselling service in Benin city, Edo state, Nigeria. Journal of Medicine Biomedical Research. 2013;12(2):150-65.

11. World Health Organization. Global health sector strategy on HIV 2016-2021. Towards ending AIDS. World Health Organization; 2016.

12. Williams BG, Granich R. Ending AIDS: myth or reality? The Lancet. 2017 Jul;22(10092):357. 390(.

13. Balcha B, Erkalo D, Beyene T. Clients Satisfaction with Prevention of Mother to Child Transmission of HIV Services in Public Hospitals of Hadiya zone, Southern Ethiopia. J Fam Med Dis Prev. 2019; (5):116.

14. Asefa A, Mitike G. Prevention of mother-to-child transmission (PMTCT) of HIV services in Adama town, Ethiopia: clients' satisfaction and challenges experienced by service providers. BMC pregnancy and childbirth. 2014 Dec 1;14(1):57.

15. Naburi H, Mujinja P, Kilewo C, Bärnighausen T, Orsini N, Manji K, Biberfeld G, Sando D, Geldsetzer P, Chalamila G, Ekström AM. Predictors of patient dissatisfaction with services for prevention of mother-to-child transmission of HIV in Dar es Salaam, Tanzania. PloS one. 2016 Oct 21;11(10):e0165121.

16. Laar AK, Amankwa B, Asiedu C. Prevention-of-mother-to-child-transmission of HIV Services in sub-Saharan Africa: a qualitative analysis of healthcare providers and clients challenges in Ghana. International Journal of MCH AIDS. 2014;2(2):244.

17. Abraham SA. "Why I stayed when others left": an appreciative inquiry of retention in the prevention of mother to child transmission of HIV in Takoradi Government Hospital, Ghana (Doctoral dissertation, Faculty of Health Sciences).

18. Opoku ET. Assessment of Implementation of the National Guidelines for Prevention of Mother-To-Child Transmission of HIV among Selected Districts in the Eastern Region of Ghana (Doctoral dissertation, University of Ghana).

19. Mosadeghrad AM. A conceptual framework for quality of care. Materia socio-medica. 2012;24(4):251.

20. Ghana Statistical Service. Population and Housing Census Report, Ghana. 2019.

Loading [MathJax]/jax/output/CommonHTML/fonts/TeX/fontdata.js 
21. Dako-Gyeke P, Dornoo B, Addo SA, Atuahene M, Addo NA, Yawson AE. Towards elimination of mother-to-child transmission of HIV in Ghana: an analysis of national programme data. International journal for equity in health. 2016 Dec 1;15(1):5.

22. Taber KS. The use of Cronbach's alpha when developing and reporting research instruments in science education. Research in Science Education. 2018 Dec 1;48(6):1273-96.

23. Torbica ŽM, Stroh RC. Customer satisfaction in home building. Journal of Construction Engineering Management. 2001 Feb;127(1):82-6.

24. Charan J, Biswas T. How to calculate sample size for different study designs in medical research? Indian journal of psychological medicine. 2013 Apr;35(2):121.

25. Mustapha M, Musiime V, Bakeera-Kitaka S, Rujumba J, Nabukeera-Barungi N. Utilization of "prevention of mother-to-child transmission" of HIV services by adolescent and young mothers in Mulago Hospital, Uganda. BMC infectious diseases. 2018 Dec 1;18(1):566.

26. Oladipo JA. Utilization of health care services in rural and urban areas: a determinant factor in planning and managing health care delivery systems. Afr Health Sci. 2014;14(2):322-33.

27. Bachore BB, Tafese F, Gebissa F, Mekango DE. Quality of Prevention of Mother to Child Transmission (PMTCT) of HIV Services in Public Hospitals of Hadiya zone, Southern Ethiopia. Health Syst Policy Res. 2018;5(2):73.

28. Naburi H, Mujinja P, Kilewo C, Bärnighausen T, Orsini N, Manji K, Biberfeld G, Sando D, Geldsetzer P, Chalamila G, Ekström AM. Predictors of patient dissatisfaction with services for prevention of mother-to-child transmission of HIV in Dar es Salaam, Tanzania. PloS one. 2016;11(10).

29. Audo MO, Ferguson A, Njoroge PK. Quality of health care and its effects in the utilisation of maternal and child health services in Kenya. East Afr Med J. 2005 Nov;82(11):547.

30. Yaya S, Bishwajit G, Ekholuenetale M, Shah V, Kadio B, Udenigwe O. Urban-rural difference in satisfaction with primary healthcare services in Ghana. BMC Health Serv Res. 2017 Dec;17(1):776.

31. Farmer J, Hinds K, Richards H, Godden D. Urban versus rural populations' views of health care in Scotland. Journal of health services research \& policy. 2005 Oct 1;10(4):212-9.

32. Afulani PA. Rural/urban and socioeconomic differentials in quality of antenatal care in Ghana. PloS one. 2015;10(2).

33. Elsey H, Agyepong I, Huque R, Quayyem Z, Baral S, Ebenso B, Kharel C, Shawon RA, Onwujekwe O, Uzochukwu B, Nonvignon J. Rethinking health systems in the context of urbanisation: challenges from four rapidly urbanising low-income and middle-income countries. BMJ global health. 2019 Jun 1;4(3):e001501.

34. Spasojevic N, Vasilj I, Hrabac B, Celik D. Rural-urban differences in health care quality assessment. Materia socio-medica. 2015 Dec;27(6):409.

35. Al Shamsi H, Almutairi AG, Al Mashrafi S, Al Kalbani T. Implications of Language Barriers for Healthcare: A Systematic Review. Oman Medical Journal. 2020 Mar;35(2):e122.

36. Sakeah E, Aborigo R, Sakeah JK, Dalaba M, Kanyomse E, Azongo D, Anaseba D, Oladokun S, Oduro AR. The role of community-based health services in influencing postnatal care visits in the Builsa and the West Mamprusi districts in rural Ghana. BMC pregnancy and childbirth. 2018 Dec 1;18(1):295.

37. Assan A, Takian A, Aikins M, Akbarisari A. Universal health coverage necessitates a system approach: an analysis of Community-based Health Planning and Services (CHPS) initiative in Ghana. Globalization and health. 2018 Dec;14(1):1-0.

38. Augustine A. Determinants of Patients' Satisfaction at Sunyani Regional Hospital: Ghana. International Journal of business social research (IJBSR). 2014;4:96.

39. Khamis K, Njau B. Patients' level of satisfaction on quality of health care at Mwananyamala hospital in Dar es Salaam, Tanzania. BMC Health Serv Res. 2014 Dec;14(1):400.

40. Alarcon-Ruiz CA, Heredia P, Taype-Rondan A. Association of waiting and consultation time with patient satisfaction: secondary-data analysis of a national survey in Peruvian ambulatory care facilities. BMC health services research. 2019 Dec 1;19(1):439.

41. Adindu A, Esu E. Waiting for health care: clients' response to waiting time at the outpatient department of a general hospital in Nigeria. Continental Journal of Tropical Medicine. 2012;6(2):16-21.

42. Assefa F, Mosse A. Assessment of clients' satisfaction with health service deliveries at Jimma University specialized hospital. Ethiopian journal of health sciences. 2011;21(2):101-10.

43. Reibstein D, Bendle N, Farris P, Pfeifer P. Marketing metrics: Understanding market share and related metrics.

\section{Figures}




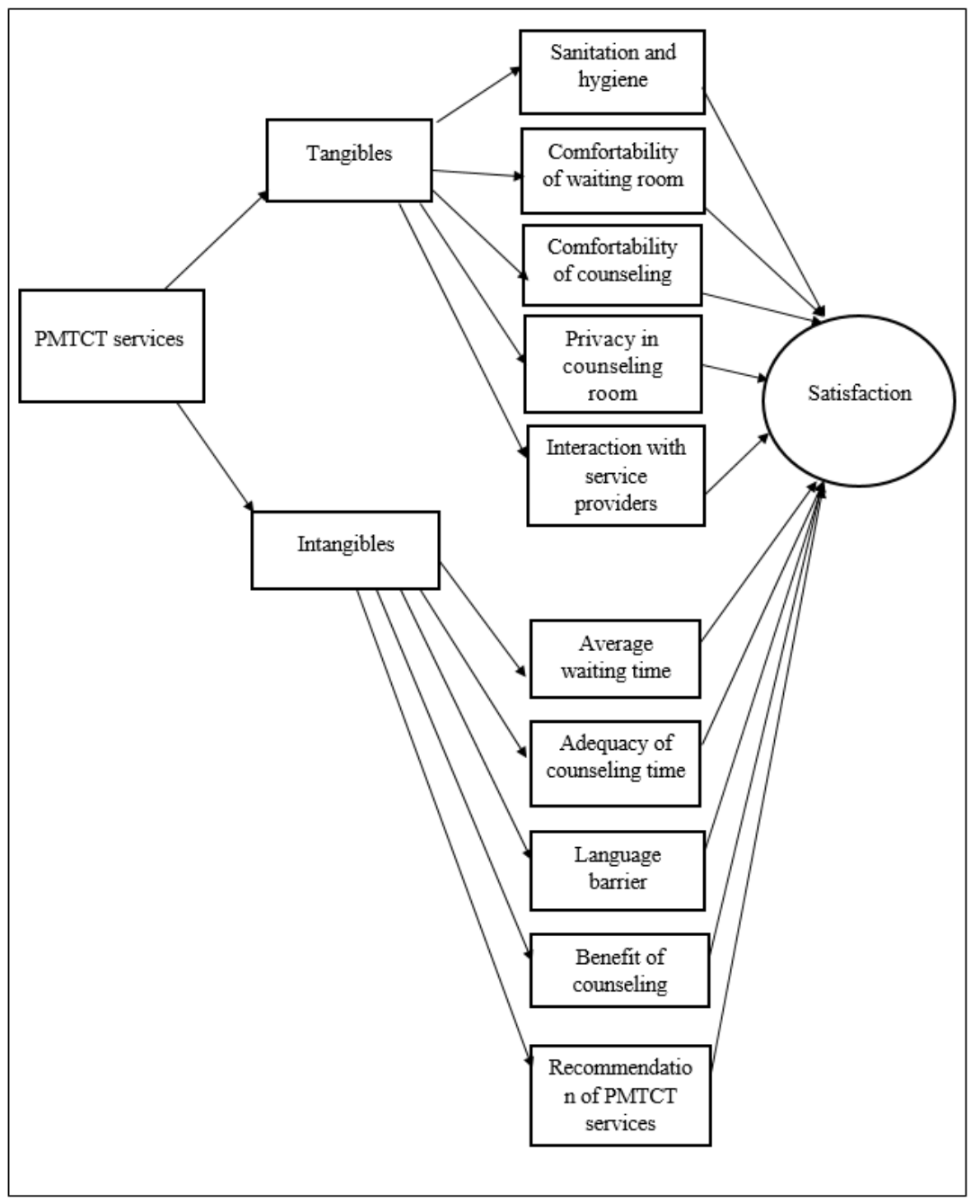

Figure 1

Conceptual framework of satisfaction with PMTCT services adapted from Mosadeghrad [19] 